\title{
Alexandra Pita (2014), Educar para la paz. México y Ia Cooperación Intelectual Internacional, 1922-1948, Universidad de Colima y Secretaría de Relaciones Exteriores, México
}

María Rosa Gudiño Cejudo

Universidad Pedagógica Nacional, Ajusco, Ciudad de México mrgudino@upn.mx

El libro de Alexandra Pita, publicado en 2014, presenta los resultados de una exhaustiva investigación que inicia con la conformación de la Sociedad de Naciones (SDN) en Ginebra, Suiza el 15 de noviembre de 1920, y centra su atención en la participación de algunos intelectuales, quienes, a través de la Organización Internacional de Cooperación Intelectual (OICI), promovieron la llamada cooperación intelectual. El principal objetivo de estos protagonistas fue buscar, durante el periodo de entreguerras, una negociación pacífica a los conflictos bélicos a través de la vía diplomática, promotora de una campaña de "desarme moral".

En este libro, se presentan a los intelectuales en su doble faceta de diplomáticos y promotores de la cultura, quienes se desempeñaron como protagonistas en esta empresa internacional porque impulsaron propuestas para cumplir los objetivos de la SDN; algunas de éstas fueron fomentar el intercambio académico de profesores, estudiantes, artistas y científicos; difundir material de bibliotecas y archivos; conformar colecciones de museos; y, la más importante, analizar el papel de la enseñanza de la historia con la revisión de manuales de texto de historia y el uso del cine como instrumento educativo.

En sus encuentros y pláticas, los intelectuales concluyeron que al mejorar los contenidos de los libros y al incorporar una historia internacional que sensibilizara a los estudiantes a conocer las historias de otros países, se construiría gradualmente una "conciencia trasformadora", como vía para fomentar el diálogo en lugar del conflicto bélico.

Entonces, la cooperación intelectual se convirtió en el eje articulador de las actividades educativas y culturales propias de la diplomacia cultural para promover la paz. Para entender estos procesos, la autora aborda, desde una perspectiva de la historia cultural de 
las relaciones internacionales, las diferentes acciones que se entrelazaron para explicar el origen de las instituciones que encabezaron este esfuerzo colectivo. Pita explica que la participación de los países americanos en este proceso está desdibujada historiográficamente, y por esto asumió el gran reto de estudiar, a través de la Comisión Mexicana de Cooperación Intelectual (CMCI), el desempeño de México en este escenario colmado de debates y propuestas.

Los intelectuales mexicanos Alfonso Reyes, Isidro Fabela, Genaro Estrada y Jaime Torres Bodet, entre otros, conformaron el cuerpo diplomático mexicano que participó de estos eventos y llamaron "Educar para la paz" a las numerosas iniciativas que condensaba el proyecto de cooperación intelectual.

Para presentar la dupla instituciones-participantes, Pita escribió siete capítulos —cada uno inicia con un epígrafe, para que el lector anticipe parte de lo que leerá- en los cuales detalladamente tejió una compleja y cambiante estructura institucional que incorporó diferentes comisiones e institutos nacionales e internacionales cuyos integrantes organizaron congresos, conferencias y pláticas que, durante veintiséis años, sirvieron de foro para sus debates. Además, la autora comparte las múltiples fuentes que revisó para escribir esta historia; ella lo refiere como parte de esa necesidad "acumulativa del historiador", pero lo cierto es que, la información que no aparece en el cuerpo del texto está incluida en las notas a pie de página que enriquecen los contextos y los eventos narrados e invitan a nuevos estudiosos a retomar el tema.

El primer capítulo de este libro se titula "La sociedad de los espíritus" e introduce al lector en los antecedentes fundacionales de la Sociedad de Naciones (SDN) y de la Comisión Internacional de Cooperación Intelectual ( $\mathrm{CICl}$ ) al finalizar la Primera Guerra Mundial, como parte de las nuevas formas en las cuales debía desarrollarse la política internacional. Para fortalecer la red institucional que siguió a estas dos primeras, se crearon las Comisiones Nacionales de Cooperación Intelectual (CNCl) con el fin de conocer las particularidades educativas y culturales de cada país miembro; en el caso de los países latinoamericanos, deberían establecer vínculos con los intereses y las prácticas de Estados Unidos que, si bien no formaba parte de la SDN, intentaba mantener el control de la cooperación intelectual en el continente.

México entró en acción al formalizarse la creación de la Comisión Mexicana de Cooperación Intelectual (CMCI), establecida en 1931 debido a que no fue invitado a participar de la SDN desde el inicio; Pita explica detalladamente los pormenores de esta invitación tardía y el contexto nacional que determinó la agenda de la política internacional mexicana a partir de su año de ingreso.

Pita explica que, después de conformadas las organizaciones, fue necesario constituir el Comité Internacional de Relaciones Intelectuales (CICl) para organizar el trabajo intelectual en un contexto de guerra. La autora expone un buen ejemplo de cómo se pusieron en prác- 
tica las propuestas de los intelectuales al presentar al Instituto de Cinematografía Internacional (ICI), creado en Roma, Italia en 1928, porque le dio al cine un lugar primordial como instrumento de difusión y promovió el intercambio de películas que podrían convertirse en agentes de formación moral e intelectual para los espectadores - la posibilidad de intercambiar filmes entre los países apoyaría la anhelada comprensión internacional y ubicaría al cine como una de las estrategias de difusión educativa para la paz.

Después de conocer cómo se crearon tanto la SDN como los institutos y cómo se promovieron las comisiones, el capítulo dos, "Entre América y Europa", expone, por una parte, las difíciles relaciones entre dos movimientos: el panamericanismo y el latinoamericanismo que pugnaron, cada uno, por una propuesta de integración regional; por otra, el papel de los Estados Unidos y las medidas que tomó para controlar la cooperación intelectual en el continente americano a través del Instituto Panamericano de Geografía e Historia (IPGH) y el Instituto Interamericano de Cooperación Intelectual (IICI).

El primero de estos nuevos institutos colocó sus oficinas centrales en la Ciudad de México y desempeñó un papel políticamente neutral, porque sirvió para proponer y revisar las estrategias dedicadas a analizar la enseñanza de la historia; el segundo, coordinó las acciones de los países americanos, y al contar con el apoyo económico de fundaciones estadounidenses como la Carnegie y la Rockefeller, cimentó la participación de los Estados Unidos, que apareció en el escenario de la cooperación intelectual internacional a través del interamericanismo impulsado por la política de Franklin D. Roosevelt.

A través de proyectos culturales o artísticos dirigidos por la Oficina de Cooperación Intelectual de la Unión Panamericana (OCIUP), se publicaron libros y manuales escritos en inglés, español y portugués; se organizaron talleres pedagógicos; y se promovieron filmes educativos y programas de radio que tuvieron como propósito que los estadounidenses conocieran la historia de América Latina y sus habitantes. La Oficina del Coordinador de Asuntos Interamericanos (OCIAA), dirigida por Nelson Rockefeller, puso en marcha programas educativos y culturales que, a través de propaganda escrita y filmes educativos, cumplían el propósito de la OcIUP.

El capítulo tres, "Educación y Cooperación Internacional", expone con detalle los primeros intentos de la SDN para configurar los planes educativos que enseñarían a pensar a los jóvenes, en la cooperación internacional. Los libros y los manuales para la enseñanza de historia, geografía e instrucción cívica incluían discursos nacionalistas, y por eso se consideraban forjadores de identidad; la revisión de sus contenidos debía tener como objetivo sensibilizar a los jóvenes hacia el mejor entendimiento de lo que acontecía en naciones diferentes a las propias, porque eso les ayudaría a valorar otras historias.

La propuesta fue incluir en los libros de texto apartados de historia internacional, y para entender mejor esta premisa, Pita reproduce los debates entre voces discordantes como la 
del diplomático español, Julio Casares Sánchez, que criticaba el "romanticismo internacional" detrás de la propuesta de escribir libros con estas características; y la del francés, Emile Borel, quien apoyaba que los libros incluyeran la historia de otras naciones y promovieran una historia mundial que ayudara a eliminar los prejuicios entre las naciones.

Ambas posturas mostraban la visión europea del asunto y se aceptaron de manera desigual entre los países latinoamericanos cuyos representantes se manifestaron en la Convención sobre la Enseñanza de la Historia (1933), realizada en la VII Conferencia Internacional Americana. Los participantes fueron contundentes al sugerir que debía erradicarse de los libros de texto el "nacionalismo exacerbado" porque daba una imagen negativa del "otro"; para formalizar su postura, redactaron ocho artículos y crearon el Instituto para la Enseñanza de la Historia de las Repúblicas Americanas en Buenos Aires.

Los mexicanos participantes firmaron el documento final de la Convención; la Secretaría de Educación Pública, en su papel de institución revisora de los textos escolares y responsable de que se incorporaran a éstos los contenidos sugeridos, gradualmente incorporó sus acuerdos; sin embargo, el contexto educativo nacional, marcado por el tránsito de la educación socialista a una basada en el nacionalismo, no contribuyó a que el proceso tuviera resultados evidentes.

Después de exponer los debates y las propuestas relacionadas con la enseñanza de la historia como una vía para alcanzar la paz, los siguientes capítulos abordan los diferentes debates en torno al papel de los intelectuales, su activa participación y los argumentos esgrimidos para equilibrar las relaciones entre los continentes europeo y americano, en un contexto en donde el avance del fascismo evidenció los límites del proyecto de cooperación intelectual internacional.

El capítulo cuatro, titulado "La república de las letras", muestra que entre los intelectuales promotores de la cooperación intelectual permeó la idea de que llevaban a cabo "una empresa intelectual legítima y legitimadora", y por eso, formaban parte de una república letrada a favor de una causa pacífica.

A través de la agrupación, Liga del Pensamiento, encabezada por intelectuales franceses que debatían sobre el papel de las ideas, se llevaron a cabo encuentros epistolares y reales para dialogar entre ellos. La carta se convirtió en una de las principales fuentes para la autora; así, la correspondencia entre intelectuales europeos y americanos publicadas entre 1932 y 1936 es la base documental de este capítulo.

A través de la revisión que la autora hizo de estos documentos, el lector conocerá qué discutían los intelectuales en torno a la cultura, qué medios utilizaron y de qué manera el intercambio epistolar dio a la carta un papel central en este cruce de ideas. En estos encuentros, participaron Genaro Estrada y Alfonso Reyes; el primero lo hizo como representante de América Latina en un encuentro organizado por el Comité Permanente de Arte y 
Letras de la SDN para discutir sobre el problema de la "cultura; el segundo, como invitado a los debates epistolares, organizados por el Comité de Letras del ॥CI para definir el papel del espíritu y su naturaleza en un orden intelectual.

La relación entre América Latina y Europa fue el tema central en los debates; Reyes, como representante del continente americano, y el francés, George Dumahel, del europeo, expusieron las particularidades de su respectivo continente, evidenciando las diferencias y la imposibilidad de aislar la situación política internacional de las discusiones sobre cultura.

"El desarme moral" es el capítulo cinco, y llama la atención el epígrafe de Aldous Huxley por su asociación de una visión higienista que aludía a la relación entre la sociedad y la guerra con la de un enfermo atacado por un virus. Salvarse de la enfermedad, la guerra, requería de medidas curativas, es decir, pacifistas. La autora menciona que muchos intelectuales se comprometieron a implementar, desde el arte y la ciencia, estas medidas a partir del llamado desarme moral; este propósito se relacionaba directamente con el tema educativo y los esfuerzos de educar a los jóvenes en un sentido internacional, como ya se discutió en capítulos anteriores.

El desarme moral debía entenderse como el impulso de una conciencia pacifista, y los debates en torno a éste fueron fundamentales a lo largo de la década de los años treinta. La autora explica que en 1932 se creó un Comité de Desarme Moral en Europa, que reunió a veintiún miembros, quienes afianzaron el uso de la radiodifusión, el cine, el teatro y la prensa como los instrumentos educativos para promover la nueva cruzada moral; la contraparte europea fue lo realizado en América, y Alfonso Reyes desempeñó un papel fundamental como representante de la Comisión de la Organización de la Paz, y más tarde, cuando se llevó a cabo la Conferencia de la Paz, fue nombrado relator general de la sexta comisión que se dedicó a los temas del desarme moral y la cooperación intelectual.

La Comisión mexicana se hizo presente diseñando numerosas actividades, relacionadas con los instrumentos educativos promovidos desde Europa y la revisión de libros de historia que se difundieron hacia el exterior y fueron puestos a revisión por vía de los memorándums que elaboraron sus representantes.

El capítulo seis, "La hora americana" muestra cómo, ante el inicio de la Segunda Guerra Mundial y la consecuente inestabilidad de los países europeos, los del continente americano buscaron convertirse en relevos para establecer en La Habana, Cuba una sede alterna para la OICI y constituir un Centro Internacional de Cooperación Intelectual (CEICI).

Las iniciativas para mantener los idearios pacifistas de la SDN y de la OICI debían mantenerse a pesar de la guerra, pero la idea no prosperó, y para explicarlo la autora describe lo que aconteció en diferentes conferencias como la de Chile (1939), en donde se promovió el posible relevo americano, así como la situación de las comisiones nacionales y sus respectivas producciones culturales y educativas. 
La participación de México en esta conferencia está enmarcada por el periodo que la autora define como la "urgencia del país por figurar internacionalmente después de la expropiación petrolera" y fue representada por Luis Chávez Orozco, subsecretario de educación pública, quien tuvo una apretada agenda con autoridades y funcionarios públicos.

"Cuando la paz sea restablecida" es el último capítulo de este libro. La oıcı había estado en un impasse entre 1939-1945, y al resurgir después de la guerra, el contexto era diferente y ya no tenía cabida. En el nuevo marco internacional, encabezado por mandatarios que ajustaron a sus intereses políticos el modelo de cooperación, los discursos del desarme material y moral se desdibujaron y perdieron su lugar. ¿Qué haría la cooperación intelectual en medio de esta nueva organización internacional? Alexandra Pita reconstruye el periodo, retoma discusiones y pláticas de la segunda conferencia de CNCI realizada en La Habana (1940), recrea juegos de palabras de algunos participantes y explica que la defensa de ideales como "la democracia, la paz y la libertad" siguió presente entre los intelectuales comprometidos con la causa.

En el contexto de la posguerra, se gestaba una nueva organización cultural: la Organización de las Naciones Unidas para la Educación, Ciencia y Cultura (UNESCO), constituida en el marco de una conferencia de educación realizada en Londres en noviembre de 1945. El mexicano, Jaime Torres Bodet, fue nombrado vicepresidente de ésta, y de inmediato se pronunció a favor de la nueva organización, pero aún más, reconoció el inevitable paso que debía darse del intelectualismo a una enseñanza más democrática.

El exsecretario de Educación Pública en México puso en la mesa de discusión la necesidad de pasar a la acción a una mayor cercanía con las "masas populares", lo cual significaba, en el terreno de la educación, combatir el analfabetismo. La revisión de los textos escolares y otras de las acciones educativas explicadas por Pita a lo largo de su libro no se descuidó, pero quizá pasó a un segundo plano.

Alexandra Pita detalla el origen de una serie de prácticas conocidas en la actualidad como cooperación internacional y diplomacia cultural y las organizaciones que las respaldaron. Al rescatar la dimensión histórica de estos procesos, la autora menciona el origen de la Organización de Naciones Unidas (ONU) y el de la Organización de las Naciones Unidas para la Educación, la Ciencia y la Cultura (UNESCO) y logra el propósito de despertar en el lector la curiosidad. 